\title{
Participatory epidemiology: the contribution of participatory research to epidemiology
}

\author{
Mario Bach ${ }^{1 *} \mathbb{D}$, Susanne Jordan ${ }^{1}$, Susanne Hartung ${ }^{2}$, Claudia Santos-Hövener ${ }^{1}$ and Michael T. Wright ${ }^{2}$
}

\begin{abstract}
Background: Epidemiology has contributed in many ways to identifying various risk factors for disease and to promoting population health. However, there is a continuing debate about the ability of epidemiology not only to describe, but also to provide results which can be better translated into public health practice. It has been proposed that participatory research approaches be applied to epidemiology as a way to bridge this gap between description and action. A systematic account of what constitutes participatory epidemiology practice has, however, been lacking.

Methods: A scoping review was carried out focused on the question of what constitutes participatory approaches to epidemiology for the purpose of demonstrating their potential for advancing epidemiologic research. Relevant databases were searched, including both the published and non-published (grey) literature. The 102 identified sources were analyzed in terms of comparing common epidemiologic approaches to participatory counterparts regarding central aspects of the research process. Exemplary studies applying participatory approaches were examined more closely.
\end{abstract}

Results: A highly diverse, interdisciplinary body of literature was synthesized, resulting in a framework comprised of seven aspects of the research process: research goal, research question, population, context, data synthesis, research management, and dissemination of findings. The framework specifies how participatory approaches not only differ from, but also how they can enhance common approaches in epidemiology. Finally, recommendations for the further development of participatory approaches are given. These include: enhancing data collection, data analysis, and data validation; advancing capacity building for research at the local level; and developing data synthesis.

Conclusion: The proposed framework provides a basis for systematically developing the emergent science of participatory epidemiology.

Keywords: Participatory epidemiology, Methodology, Participatory research, Health promotion, Capacity building, Context, Conceptual framework

\section{Background}

Epidemiology provides the empirical foundation for public health. In its history, the discipline has contributed in many ways to identifying various risk factors for disease and to promoting population health. Over the last decades, epidemiology has developed models utilizing genetic, population, and environmental data to create

\footnotetext{
*Correspondence: BachM@rki.de

1 Robert Koch Institute, Berlin, Germany

Full list of author information is available at the end of the article
}

knowledge relevant for policy makers and public health practice [1-3]. This includes describing the characteristics of populations (e.g. community diagnosis) and individuals; identifying risks for disease as well as the factors associated with good health; and evaluating treatment approaches and public health programs. Epidemiology has refined its methods over time in order to provide more accurate measures to serve these various purposes [1].

However, some aspects of epidemiology are still in a process of development. The call voiced by Stallones [4] 
in 1980 for an expanded view on causation of disease is of continued concern [5-9]. Stallones' critique can be summarized under two headings. First, a sometimes simplified view on the various antecedents of health can hinder complex modeling, what scholars have labeled biomedical individualism or individualization of risk [10, 11]. Second, the application of theories about the connection between risk exposure and outcome often remains incomplete (the so-called black box paradigm). As a consequence, there are difficulties within epidemiology in terms of integrating individual-level with social and environmental-level risk factors [12]. There are also problems identifying factors which are the result of interactions between individuals (e.g. community-based initiatives) and social or political organizations (e.g. public health programs) [13]. Finally, although the discipline takes into account several macrosocial determinants of health (e.g. urbanization, migration, corporate practices within industries) [14-16] and the social determinants of health [17], it still faces problems in explaining "the complexity of disease occurrence at various and interacting levels" [18, p. 218]. Consequently, these challenging issues can cause problems in knowledge translation and public health program development [19-21] and thus raise the question whether epidemiology is still the basic science of public health [22]. It has been asked what would be necessary to preserve and advance the role of epidemiology [23].

We suggest participatory research as a way to enrich epidemiologic methodology in order to address some of these challenges. Participatory research has its "basis in broad social movements striving for a more democratic and inclusive society. There is a shared recognition that science is more than adherence to specific epistemological or methodological criteria; it is primarily a means for generating knowledge to improve people's lives" [24, p. 5]. Over the past 20 years, several authors have called for more participation in epidemiologic research $[6,19$, 25, 26]. Participatory forms of epidemiology are being conducted under various labels, including popular epidemiology [27], lay epidemiology [28], community-based research [29], and participatory health research [30]. The hallmark of participatory approaches in epidemiology are equitable research partnerships with a diverse group of stakeholders such as policy makers, public health professionals, health activists and community representatives from the populations "under study". These partnerships are useful in identifying the causes of health problems and in finding strategies to address them.

The purpose of this paper is to illustrate the potential of participatory epidemiology for enhancing the quality and effectiveness of epidemiologic research through such partnerships. A scoping review was carried out on the question of how participatory approaches are being applied in epidemiology currently, contrasting these approaches with more common forms of epidemiologic research in the various stages of the research process. The result is a conceptual framework which researchers can use to advance study design and to inform their research practice. The framework provides principles to better address social complexity (e.g. the social and cultural determinants of health), contextual factors (e.g. environmental justice), as well to ways for disseminating findings so as to have a greater impact.

\section{Methods}

To explore the emerging field of participatory approaches in epidemiology, a scoping review [31,32] was conducted encompassing original studies, conceptual articles, book chapters, and reports (grey literature).

Firstly, a hand search conducted by the authors generated 71 manuscripts addressing participation in epidemiologic research. All manuscripts were read and relevant terms for a database search were extracted. This resulted in the following seven individual search terms: participatory, epidemiol*, local, health, community, health report*, indicator* and nine compound terms: hard to reach, health promotion, health reporting, needs assessment, minority health, vulnerable groups, vulnerable population, peer research, and program evaluation.

Secondly, six databases (EMBASE, SciSearch, PubMed, Scopus, Web of Science, Bielefeld Academic Search Engine) were searched (title, abstract, keywords) using different combinations of the search terms (AND operator), going back to 1970. After duplications were removed, 820 records remained. All titles and abstracts were screened using the following inclusion criteria: (1) the level or phase of participation is specified, (2) social and/or environmental determinants of health were taken into account, and (3) the relevance for public health practice was considered. This resulted in 102 sources being included in the development of our framework.

Thirdly, the included sources were analyzed based on the principles of a realist synthesis. Originally, realist synthesis was developed as an interpretative approach for studying interventions requiring a more complex assessment [33-35]. In our study, the approach was iteratively applied to appraise the evidence as found in the included sources with regard to how (e.g. collaboration with key stakeholders), why (e.g. goals like capacity building), and where (e.g. contextual factors) participatory approaches to epidemiology have been applied. More specifically, we investigated how the reported participatory approaches informed the design of the included studies with regard to the steps of the research process. Hence, we synthesized the identified participatory procedures to draw 
generalized conclusions on the approach which we subsumed under the label participatory epidemiologic practice.

Finally, a comparison between common research approaches and participatory research approaches in epidemiology were discussed and summarized (Table 2).

\section{Epidemiology and participation}

We begin by providing an overview of the cited studies underpinning our framework with regard to the following aspects of the research process: defining the research goal, defining the research question, defining the population, reconsidering context, synthesizing heterogeneous data, managing the research process, and disseminating findings (Table 1). We then discuss each aspect by comparing common approaches to epidemiologic research to participatory approaches. At the end of this section, a summary of the framework with a point-by-point comparison is provided (Table 2).

\section{Defining the research goal}

Epidemiology has developed alongside changing concepts of health and disease, pursuing different goals for disease control and prevention, particularly for populations at risk [21, 59]. Historically, the definition of research goals in epidemiology has often referred to the wider "circumstances $[\ldots]$ under which human disease is prone to develop" [60, p. 539]. But over time the definition narrowed, influenced by biomedical, causal, and downstream perspectives.

In the nineteenth century, a miasmatic paradigm of illness and death was predominant, accompanied by an epidemiology focused on the improvement of sanitation and the drainage of urban areas, often in collaboration with non-medical professionals, like engineers and local activists. Such endeavors are early examples for stakeholder participation that lay ground for collectively defining the goals of research, as is the case in a study on sanitation in urbanized areas in nineteenth-century Germany [36]. Later, the discovery of microbes led to a switch towards the germ paradigm which "opened the era of infectious disease epidemiology, in which epidemiologists have typically sought to relate a single agent to a specific disease" [61, p. 18]. Hence, the environmental and societal aspects of health were no longer the primary subject of epidemiologic research. With the rise of infectious disease epidemiology, the focus on pathogens, disease process, and the control of risk factors at the individual level has prevailed, constituting much of molecular, cell, and chronic disease epidemiology, as well $[8,20,21]$. This has been dominated by a "downstream" biomedical perspective on health problems, versus looking "upstream" to the contextual or social antecedents of health and disease
[62]. More recently, there is renewed interest in the social determinants of health and in ecological modeling, with efforts to integrate upstream and downstream reasoning in study designs [18, 63].

Participatory approaches to epidemiology can contribute to defining research goals which are relevant for both academic researchers and public health practitioners, as they often focus on the antecedents of health and thus provide an empirical basis for achieving health equity through social and political action [64]. A good example is the Youth Empowerment Strategies (YES!) AntiViolence Program in Richmond, California (USA). Young adolescences are empowered to take action on health topics which they identify using photovoice. Photovoice is a method by which people can identify various healthrelated issues through photographic techniques as a starting point for further research or community action. In a group-level research process, data is generated which is suitable for both qualitative and quantitative forms of analysis [38]. In YES! the adolescents produce data on the relationship between their environment and several dimensions of health-related behavior on which public health interventions can be based [65].

In summary, the common understanding of the research goal in participatory research lends itself to social and political outcomes. Thus, epidemiologists can profit by widening the scope and the aims of their studies.

\section{Defining the research question}

Epidemiologic studies are usually conducted within academic institutions or by public health agencies in charge of safeguarding population health, the latter with the goal of providing evidence for health-related policy making. Hence, the definition of research questions and research priorities are typically driven by an academic agenda, which has been criticized as being too narrow [11]. There are several fields in epidemiology in which it is not immediately apparent how the research questions can be developed together with practitioners and the researched populations, for example, in clinical epidemiology. But even fields like genetics could profit from at least having their questions validated by practitioners, as shown in a project on the application of human genomic information for public health practice [66].

By applying a participatory approach, epidemiologists are able to identify the research questions that are meaningful to those immediately affected by the issue, providing knowledge which is more relevant for program development in public health $[64,67,68]$. In research partnerships, the generation of evidence is directly connected with advocacy and activism [30, 39]. People are empowered to have an influence on study design including the development of research questions [69]. For 


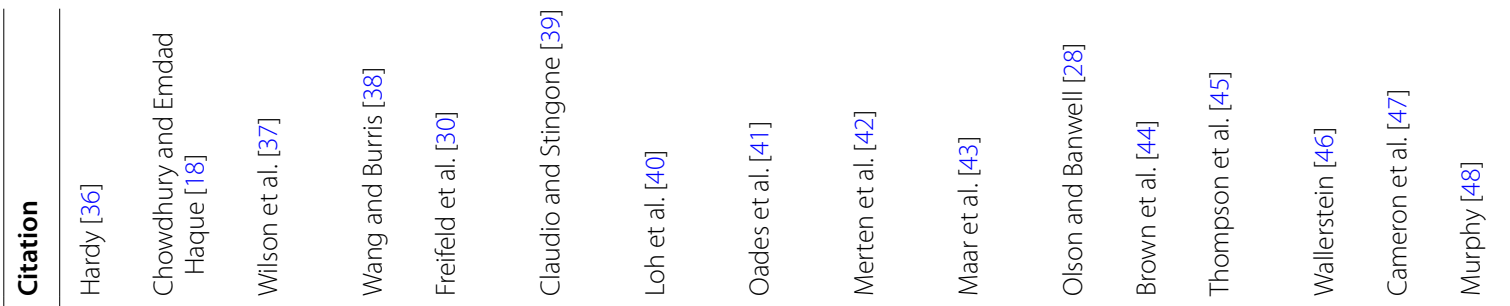

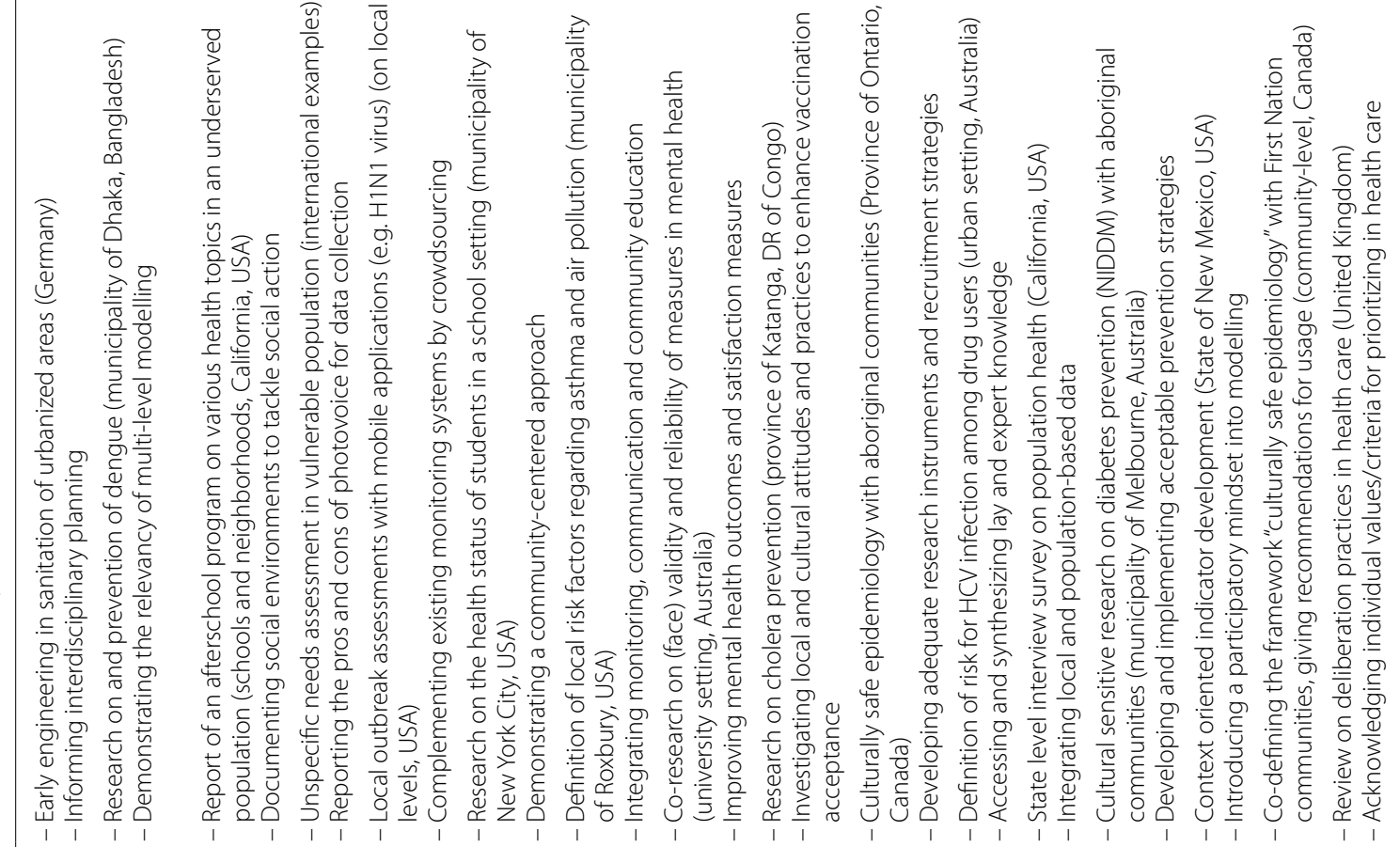

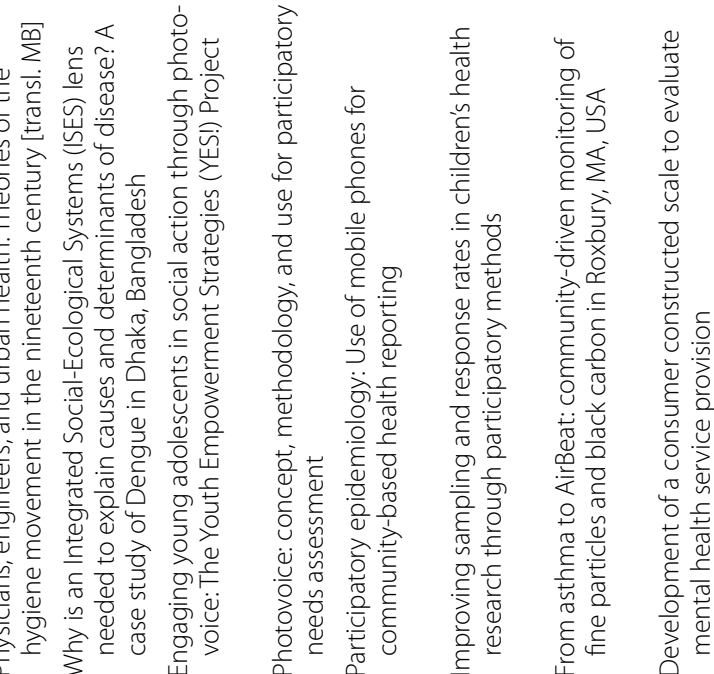

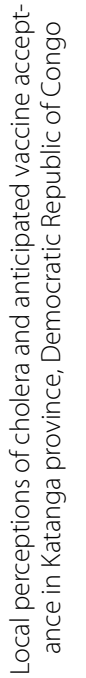

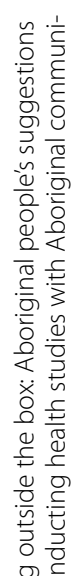
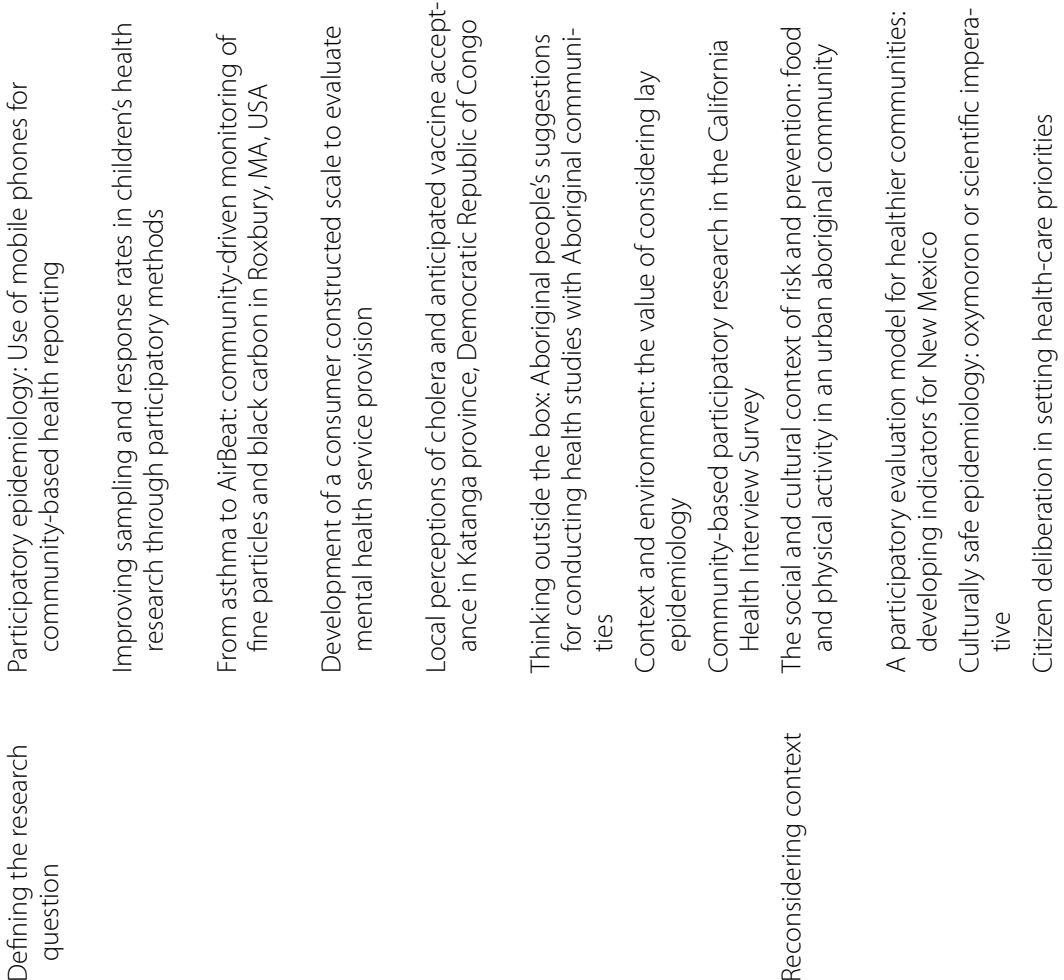


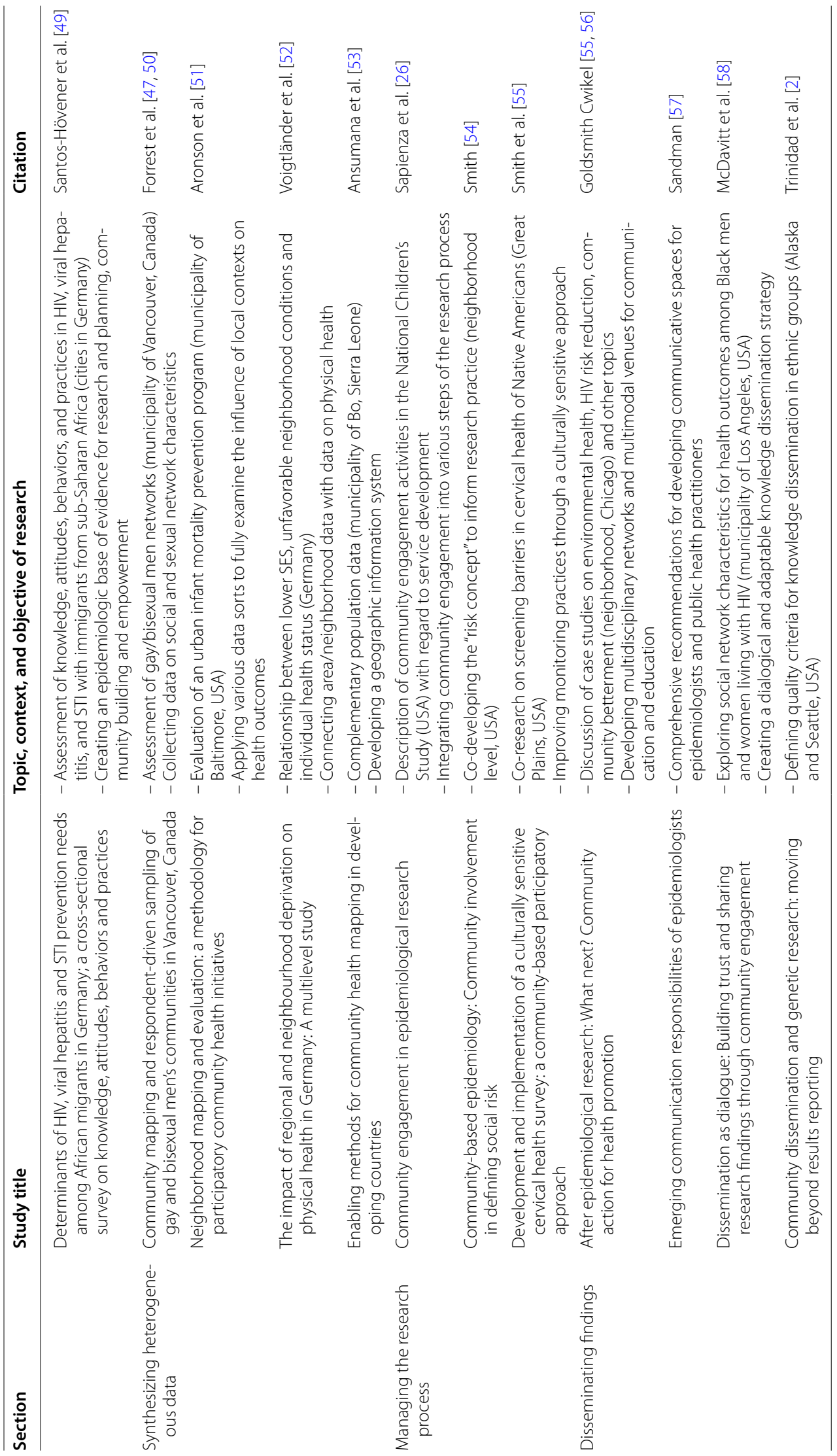


Table 2 Seven aspects of participatory research in epidemiology

\begin{tabular}{|c|c|c|}
\hline Aspects & Common epidemiologic practice & Participatory epidemiologic practice \\
\hline Defining the research goal & $\begin{array}{l}\text { - Identification of molecular, cell-level, individual, } \\
\text { group-level, and environmental risk-factors } \\
\text { - Identification of social and other determinants of } \\
\text { health } \\
\text { - Specific focus preferred }\end{array}$ & $\begin{array}{l}\text { - Identification of individual, group-level, and environ- } \\
\text { mental health promoting factors } \\
\text { - Aims to change social and other determinants of } \\
\text { health } \\
\text { - Strives for comprehensiveness }\end{array}$ \\
\hline Defining the research question & $\begin{array}{l}\text { - Driven by academic agenda, political imperatives, or } \\
\text { unforeseeable events } \\
\text { - Research object defined by professional system } \\
\text { - Questions developed by scholarly persons }\end{array}$ & $\begin{array}{l}\text { - Driven by group-level or local needs, political agenda, } \\
\text { or unforeseeable events } \\
\text { - Research subject defined by professional and lay } \\
\text { system } \\
\text { - Questions developed by scholars, practitioners, and/ } \\
\text { or lay persons }\end{array}$ \\
\hline Defining the population & $\begin{array}{l}\text { - Statistically relevant attributes applied } \\
\text { - Individual level criteria preferred } \\
\text { - Social criteria applied (group level and higher levels) } \\
\text { - Macrosocial criteria applied }\end{array}$ & $\begin{array}{l}\text { - Socially and politically relevant attributes applied } \\
\text { - Individual criteria may be considered } \\
\text { - Relies on social criteria (group and local level preferred) } \\
\text { - Macrosocial criteria maybe applied }\end{array}$ \\
\hline Reconsidering context & $\begin{array}{l}\text { - Research on supranational, national, regional, and } \\
\text { local level } \\
\text { - Environmental, cultural, or social contexts may inform } \\
\text { modeling } \\
\text { - Multilevel modeling preferred }\end{array}$ & $\begin{array}{l}\text { - Local level preferred, regional or state level may be } \\
\text { considered } \\
\text { - Environmental, cultural, or social contexts explicitly } \\
\text { inform modeling } \\
\text { - Ecological modeling preferred }\end{array}$ \\
\hline Synthesizing heterogeneous data & $\begin{array}{l}\text { - Leading paradigm quantitative (complemented by } \\
\text { qualitative methods) } \\
\text { - Data collection and analysis oriented towards measur- } \\
\text { able factors } \\
\text { - Specific validity criteria (granted by standardized } \\
\text { methods) }\end{array}$ & $\begin{array}{l}\text { - Leading paradigm qualitative (complemented by } \\
\text { quantitative methods) } \\
\text { - Data collection and analysis oriented towards local } \\
\text { and/or systemic change } \\
\text { - Specific validity criteria (granted by equitable research } \\
\text { principles) }\end{array}$ \\
\hline Managing the research process & $\begin{array}{l}\text { - Research is planned and driven by scholarly persons } \\
\text { - Predefined research protocols applied } \\
\text { - Stringent sequencing of steps ensures quality }\end{array}$ & $\begin{array}{l}\text { - Research is planned and driven collaboratively } \\
\text { - Recursively adapted research protocols applied } \\
\text { - Adaptive sequencing of steps ensures quality }\end{array}$ \\
\hline Disseminating findings & $\begin{array}{l}\text { - Various formats (scientific publications, reports, } \\
\text { advisory services) } \\
\text { - Implementation usually delegated (depending on } \\
\text { mandate) }\end{array}$ & $\begin{array}{l}\text { - Various formats (educational programs, community } \\
\text { based initiatives, scientific publications, reports) } \\
\text { - Implementation in practice (alongside research } \\
\text { process) }\end{array}$ \\
\hline
\end{tabular}

example, a participatory research design was applied in the community-driven monitoring study AirBeat on the links between high asthma rates and air pollution in a Boston (USA) neighborhood. Reliable data were produced on the long-term effects of air pollution at the community level [40]. The subsequent steps in the monitoring and communication process were planned in frequent meetings of researchers and community members. The AirBeat project illustrates how the identification of meaningful research questions in partnership with local people can itself be an integral part of the study design. Participatory research offers various methods to facilitate such processes [70].

However, there can be a tension between the desire of community groups to address broader issues and the focus of epidemiologists on highly specific issues of causality [71]. One possible solution is a sequencing of methods, as was shown in the participatory development of consumer constructed scales in the field of mental health. First, an interdisciplinary team of university-based researchers developed a first draft of scales. Second, consumers were involved in generating and validating the specific items. This is a quite common approach in consumer research, more generally, with consumers and researchers working as equal partners [41].

In summary, the definition of the research questions in participatory research is based on a consensus regarding the common goals of all project partners. This consensus rests on both the interests and needs of those involved and on the relevant ethical and political issues identified early in the research process [72, 73]. For epidemiologists, collaboratively defining the research question strongly challenges their own "role and legitimate boundaries" [74, p. 589] at the same time new opportunities for developing research studies arise.

\section{Defining the population}

Defining the population under study is complex. Individual, social, cultural, and environmental factors represent only a small selection of possible characteristics, the interactions between them adding a further dimension. Commonly, a "case-centred epidemiology 
identifies individual susceptibility, but it may fail to identify the underlying causes of incidence" [75, p. 432]. Nevertheless, in many epidemiologic study designs, the researched populations are aggregated by individual attributes with the goal of answering questions regarding disease causation and distribution (methodological individualism) [76]. Recent developments in epidemiology seek to address this limitation. For example, multilevel modeling can include individual, societal (e.g. neighborhood) and regional characteristics [52]. Participatory epidemiologic research routinely makes use of characteristics that go beyond the individual level and can thus expand on other forms of modelling. For example, through a collaboration between epidemiology and anthropology, which has enhanced the recognition of local and tribal perceptions of health and disease as well as the recognition of factors triggered by globalization and emigration, thus providing sophisticated criteria to define the population under study [77, 78]. This practice avoids colonialist views on health and disease and thus can enhance the impact of public health interventions. Such an approach was recently reported in the field of vaccine acceptance in the Democratic Republic of Congo where local perceptions on health and culturally-based practices influenced the definition of the population under study [42]. Another example for participatory research in epidemiology is a culturally sensitive recruitment strategy that was developed with aboriginal communities in Ontario, Canada in the field of diabetes prevention [43].

The strengths of such approaches is the acknowledgement that "people live in complex, interconnected, and dynamic contexts" [79, p. 822]. Epidemiologists could benefit from recognizing this perspective when defining and seeking access to certain populations. This can help, for example, to improve the quality of the data on the perception and reporting of risks in specific communities, e.g. drug users, in order to support "situated health care responses" [28, p. 91].

To some extent, participatory approaches can also be applied in large-scale surveys in order to better reach certain populations. This was shown in the California Health Interview Survey in which participatory approaches informed many phases of study planning and implementation. This included several outreach activities informed by inputs "from many state and local public health agencies, health care organizations, the academic community, and advocacy groups through a series of public meetings, [and] key informant interviews [...]" [44, p. 2].

In summary, the cited studies clearly demonstrate that collaborations between researchers, local groups, and public health institutions on various levels offer several methods for a joint definition of the relevant population which takes into account various levels of disease causation and public health intervention.

\section{Reconsidering context}

"Throughout the history of public health, depending on the theory of disease causation prevalent at the time, different aspects of individuals and their environments have been considered important as potential causes of disease" [12, p. 216]. Accordingly, the notion of context has changed over time: Until the 1990s, it was criticized that epidemiology did not include group or macro-level variables in study design [12, 62, 80]. As a response, multilevel modeling has become a common approach, but the integration of such models in an overarching design remains challenging, given that each level interacts with different contexts [81]. Ecological models are also being applied, accounting for various contexts by applying interdisciplinary approaches to address issues of complexity [18]. Also, social epidemiology and cultural epidemiology are exploring historically grown contexts by examining locally constructed meanings of health and illness [78] and by studying socially developed practices and their impact on health-related outcomes [45].

In participatory research, context plays a central role. Local contexts are emphasized, requiring that the study design be adapted to the place, as well as to the interests and needs of the co-researchers from the population "under study" both in the interest of achieving health equity. Such a contextualization of research has a strong impact on modeling. This was demonstrated in a participatory evaluation model to develop health statistics for the state of New Mexico (USA). Contextualizing took place by integrating "private and public agencies, community groups, schools, higher education, and tribal entities [...]" through "community-based decision-making and improved service coordination" [46, p. 199f]. Another example of contextualization is the crosssectional survey on knowledge, behavior and attitudes regarding HIV, viral hepatitis, and sexually-transmitted infections among immigrants from Sub-Saharan Africa in Germany. The Robert Koch Institute (the national public health institute in Germany) is applying a participatory research design to collect data in different German cities, together with community representatives of the researched population. Several strengths of the communities are being recognized as being both important to the context and important for the research outcome, such as peer support in the form of advice from community members on certain behavior and attitudes [49].

It should be noted, however, that contextualization through a participatory process can cause conflicts. Conflicting goals among the diverse stakeholders-communities, policy makers, activists, and researchers-are 
not uncommon. And conflicts can arise regarding the translation and implementation of knowledge into local structures. Both aspects are reported in the evaluation study on health statistics in New Mexico (cited above) [46]. This study demonstrates that participatory research is challenged by asymmetric goals, needs, and power relations among the stakeholders. Interestingly, another study in the same context reported that the commitment among the stakeholders applying a participatory approach clearly outweighed these conflicts. By acknowledging the value of intermediate outcomes the collaboration can be sustained [82].

Epidemiologists can profit from such experiences, being inspired by how to contextualize their goals, questions, and methods. This is especially important in research with communities who have rejected the usual epidemiologic instruments as being inappropriate, as was reported in a study with First Nations in Canada [47]. Another way which the principle of contextualization is being applied is to prioritize research topics through citizen deliberation [48]. By using participatory research methods, epidemiologists can explicitly take into account contextual factors in order to make their research and the produced knowledge more applicable and relevant to practice.

\section{Synthesizing heterogeneous data}

In health research various sorts of qualitative data (e.g. narratives) and quantitative data (e.g. statistical data) are being retrieved to answer research question concerning individuals, groups, localities, regions or even worldwide systems (e.g. global health). The applied methods for synthesizing data differ, depending on the underlying research paradigm such as positivism (e.g. experimental design), constructivism (e.g. interpretative design) or critical theory $[25,83]$.

Epidemiology is characterized by a positivist stance. This means that data collection and analysis is focused on factors which can be measured in a strict sense (quantification). Epidemiologic research has developed standardized statistical methods of increasing sophistication, basing the explanatory power of a study on the mathematically tested strength of relationships between the variables in various forms of modelling. The challenge lies in finding the "right" instruments to maximize predictive performance [84]. In the interest of feasibility (and parsimony), exposure-outcome-relations are modeled using a restricted set of variables, which may include social and other contextual factors. Even sophisticated methods of quantitative research are limited, however, as they have difficulty capturing problems related to disease and health for which quantitative data is not available or for which there are severe limitations to measurement.
By applying participatory approaches, epidemiologists can adopt a "realistic" stance, and, thus, a more grounded approach to the generation of data. Actually, this is not new in epidemiologic research practice. In the 1960s and 1970s, holistic approaches were developed to incorporate social and cultural factors in community-based models of disease [11]. In the last two decades, ecological modeling has become increasingly popular as a way to take into account complex circumstances in theory building and research design [5, 10, 18, 25].

Participatory epidemiology, as presented in this paper, also depends on such models. In general, participatory research utilizes heterogeneous data from different sources addressing different levels (e.g. individual, communities, networks). In the research process, either qualitative or quantitative methods can be applied, or both. The involvement of various stakeholders in the research process necessitates additional criteria for internal and external validity. These include, amongst others, intersubjective validity (the extent to which the research is viewed as being credible and meaningful by the stakeholders) or catalytic validity (the extent to which the research is useful in terms of presenting new possibilities for public health action) [24]. These forms of validity are aimed at assuring the relevance of the research for all those involved, so that the findings can be used directly to address public health issues.

For example, the method neighborhood mapping or community mapping is a well-established participatory approach which is also common in epidemiology. Such methods are suitable to describe the "social geography" of certain populations, for example to generate data on reported network size or ethnographic data, as demonstrated in a study with gay and bisexual communities in Vancouver, Canada [50]. Neighborhood mapping was also applied in an ecological study on urban infant mortality to inform program development in Baltimore, Maryland (USA). Based on a participatory community evaluation, a conceptual model was developed which comprised physical (e.g. built environment), social (e.g. organizations, norms, behavioral systems) and individual (e.g. characteristic of the mothers) factors. This model informed data collection (geocoding and map generation) to create community-based indicators for certain risks regarding infant mortality [51]. Even though environmental variables are already frequently included in epidemiologic modelling [52], participatory forms of mapping enable epidemiologists to obtain a more finegrained data [53].

In summary, participatory research provides a framework that allows new ways for retrieving and synthesizing heterogeneous data through a collaborative process. 


\section{Managing the research process}

In common epidemiologic approaches, the steps in a research process are planned and driven solely by academic experts following a predefined research protocol to ensure valid findings. In participatory approaches, research is planned and conducted by academic researchers together with public health practitioners and community partners [64]. This is made possible by applying a set of participatory practices for the co-production of knowledge, which often have the dual goal of producing epidemiologic evidence while contributing to concrete public health interventions $[26,54]$. The academic researcher is often in the role of facilitating the research process, or s/ he can serve as a consultant or team partner in a research process managed by practitioners and/or community groups. The close relationship between the generation of evidence and the design of interventions to affect health outcomes has several implications for the temporal order and the dynamics of the research process. The development of an appropriate protocol, including the choice and application of methods, is an integral part of the collaborative research process. And the knowledge gained is intended to have an immediate relevance for advancing practice on specific health issues. Accordingly, participatory approaches are characterized by a cyclical, iterative process of development, implementation, adaptation, and interpretation by academics, practitioners, and representatives of the researched population [64].

For example, the data quality for both scientific purposes and for public health practice can be enhanced by introducing a flexible design that allows integrating various perspectives on a certain health topic. This was demonstrated in a study on the relationship between exposures to toxic chemicals and thyroid disorders applying a community-oriented design: "Such a[n] [approach] would foster communication and prevention measures within communities often left out of the dissemination of information about risks identified in studies conducted with residents of these communities" [71, p. 863]. Another example is the US-based National Children's Study [26]. Participatory principles informed several steps of the research process including planning (e.g. focus groups complemented by literature reviews), study development (e.g. joint development of community engagement strategies), recruitment and data acquisition (e.g. a peer research strategy), and the dissemination of findings (e.g. community-level publications and educational programs). Participatory management of this sort can also be applied in smaller research projects, as seen in a study on variances in mortality rates caused by cervical cancer. A "culturally sensitive cervical health survey" [55, p. 67] was developed in several steps, applying participatory principles to better explain variances between certain groups of Native American and Caucasian American in an area in the Great Plains (USA). These studies demonstrate that participatory research in epidemiology can be strongly connected with democratic principles that enable and sustain dialog and joint planning.

In summary, the adaptive nature of participatory research, which allows utilizing data for various purposes, makes participatory approaches valuable to use in epidemiology.

\section{Disseminating findings}

It is well understood that the translation of epidemiologic knowledge into "appropriate policy, programs, and interventions [is] inherently tricky, and often politically controversial" [56, p. 375]. A recently published review of epidemiologic textbooks concludes that even such publications do "not readily extend to methods suitable for assessing public health problems and priorities" [21, p. 1]. Even social epidemiologists can fail to give relevant recommendations for policy makers or other stakeholders in public health practice [85]. There is a longstanding and controversial discussion on the responsibility of epidemiologists to disseminate findings in a way that goes beyond providing information and advice [56, 57]. Thus, questioning and discussing the mandate and the future role of epidemiology in public health continues to be relevant $[9,61]$.

One crucial aspect of dissemination is the relevance of the findings. Relevant are findings which connect the realms of academic research, policy, and public health practice [86]. Participatory research approaches strive explicitly for a high level of relevancy among the stakeholders by applying dialogical methods for the co-production and dissemination of knowledge [58]. Participatory research also offers several ways for epidemiologists to disseminate their findings beyond the scientific community. For example, by using focus groups to find appropriate criteria to communicate genetic research information, as shown in a study with native people in Alaska (USA) [2] or by developing culturally appropriate recommendations for public health interventions, as shown in a study with First Nations in Canada [47].

In summary, participatory research is an approach that can help to disseminate epidemiologic findings through communicative venues with a reach beyond the scientific community. These venues can be organized locally by stakeholders, setting an example for participatory research management in other contexts. In addition, since participatory research involves the population "under study" in research, the dissemination of findings can be achieved earlier and can also reach the coresearching populations more directly [87].

Table 2 provides a summary of the foregoing results. With regard to the seven aspects of the research 
process, we compare the most common approaches to epidemiologic research and participatory approaches to epidemiology.

\section{Discussion: advancing participatory epidemiology}

As with other forms of participatory health research, participatory epidemiology is an emergent science. As such, several issues need to be addressed if the approach is to be applied on a wider scale $[6,70,73]$. These issues include the following:

\section{Making use of existing data}

An initial step in several participatory health projects is finding ways to use existing data for the purpose of defining the health issue and/or for the purpose of measuring the impact of interventions. This includes both surveillance data and more general epidemiologic research on health risks. Surveillance data is often not available at the level of community interventions [88], requiring additional data gathering or an extrapolation of findings from a higher level of aggregation to the locality under study. The application of other research is also limited by the frequent lack of contextualization, as described above. However, general findings identifying risks in certain groups or places can be an important starting point for specifying the research goals and questions in a participatory epidemiologic study. Making use of existing data requires creating ongoing collaborations between public centers for epidemiology, academic institutions, and those conducting research.

A good example for such a strategy is the online data collection and monitoring system for New Mexico's Community Health Councils (USA), which was developed collectively by applying a participatory evaluation design. The result is a system which has relevance for both public health professionals and the wider community [82]. Participatory planning and other dialogical methods ensured the development of locally suitable and relevant indicators. Epidemiologists can engage in such projects to develop locally relevant indicators. Furthermore, such monitoring systems can contribute to the "regionalization" of data, which is still a challenging task in epidemiology $[89,90]$.

\section{Capacity building on the local level}

The limited applicability of existing data to local contexts requires capacity building at the local level for collecting and analyzing epidemiologic data. This, in turn, requires a close collaboration between public centers for epidemiology, academic institutions, and those conducting research at the local level. Capacity building relates to different organizational levels $[91,92]$ and may involve actors pursuing different objectives [93]. However, academic researchers, public authorities, public health practitioners, and representatives of local communities can work together to develop "collaborative capacity" [94]. In participatory research, such collaborations are starting points for the identification of locally relevant health topics and the development of collaborative practices for data collection, analysis, and planning [95]. To take action, these collaborations also need to develop "agency capacity", in order to address, for example, certain risks in vulnerable populations [96]. Participatory approaches to research can frame such endeavors by applying reciprocal research practices [97].

For epidemiologists, engaging in such collaborations can bridge the gap "that exists between those who use computational data and those who use [often locally based] cultural and linguistic models to generate their explanations" [67, p. 1135].

\section{Expanding the repertoire of methods}

As described above, the type of data typically gathered in epidemiologic research can lack crucial information which stakeholders need to address public health issues. Particularly information related to social and political determinants of health are often missing, and such information is often best captured in mixed methods or qualitative studies, producing narratives of how health problems arise and how they can be alleviated $[98,99]$.

In participatory research various methods can be integrated [24]. This can result in a generation of data with a higher level relevance, for example, regarding sensitive and stigmatized health issues $[55,100]$ or the reconstruction of individual and group-level legacies influencing the health status of certain populations [78]. This methodical enhancement is possible because participatory research promotes the systematic reflection on underlying power relations in the research process through dialog, recursive methods of understanding, and joint planning. Community-validated measures are, however, not necessarily valid and reliable in a broader sense, at least not in the eyes of academic researchers, because the community partners are focused on promoting change in their specific context [101]. Academic researchers are thus challenged to be flexible in choosing, sequencing, and adapting research methods in a way which may not meet their usual standards.

One example for an expanded epidemiologic approach is the development of a monitoring system of fine particles and black carbon in Roxbury, MA (USA), where various media, stakeholder meetings, and communitylevel educational programs have been used to develop an appropriate and acceptable methodology [40]. 


\section{Applying multiple perspectives in data synthesis}

There have been tremendous gains in the theory and practice of data synthesis over the last 20 years, with the pooling of large data sets and various forms of meta-analysis allowing for more powerful studies examining the causes of disease and health [102, 103].

Most relevant for participatory forms of research are approaches such as mixed methods reviews [104] and realist reviews [105] which are based on various forms of triangulation [103]. These approaches can enhance data synthesis in different ways. Firstly, by taking into account the heterogeneity of available data, such as program data, surveillance data, data from smaller studies, and narratives from the research populations (data triangulation). Secondly, by integrating and utilizing the perspectives of academic researchers and the co-researching practitioners and community members (investigator triangulation). Thirdly, by applying different theories on study design, e.g. theories that describe local health issues (theory triangulation). Fourthly, if needed, by combining and sequencing different methods for data synthesis (method triangulation) [106, 107]. Such approaches may also include the aforementioned participatory forms of validation.

Epidemiologists can profit from such approaches when local knowledge (e.g. expert opinion and the experiences of communities) is needed to conduct research to support public health interventions [103]. There is still much work to be done on developing these approaches. But their use is important if epidemiologists and local researches are to gain the most from the wide range of data sources, methods, and theories available for their work.

\section{Making explicit the theoretical foundation}

There is a longstanding debate regarding which theoretical basis is appropriate for epidemiology, with several claiming that the lack of theory is one of the central problems epidemiology faces [5, 10, 74]. Approaches like the ecosocial theory of disease distribution $[8,23]$ are addressing explicitly and comprehensively the various sociopolitical dimensions of health. As such, they provide an ideal theoretical basis for participatory epidemiology with its concern for the social and political causes of health and disease and how to address them. These causes include, for example: social policy; social structures; social determinants as factors measurable at the individual level; psychosocial exposures; history; and biological pathways of embodiment. The ecosocial theory not only grounds participatory epidemiologic studies in a larger body of knowledge, but it also honors and supports researching disease and illness in a larger context.

In this sense, an integrated social-ecological systems lens was applied in a study on dengue in Dhaka
(Bangladesh) to define infectious disease drivers [18]. By applying interdisciplinary theories and systems thinking, researchers were able to explain causes and determinants of dengue on different systems levels. Additionally, recommendations on the household, municipality, and regional levels were provided.

\section{Adding quality criteria}

Epidemiologic evidence rests upon quality criteria such as randomization, controlling for confounders, and replicable study protocols as part of a large battery of standardized research procedures [108]. Given that participatory epidemiology differs in method and theory from several other epidemiologic approaches, it needs to set quality criteria which will necessarily differ in some respects from the usual epidemiologic standards. At the same time, participatory research provides quality criteria which "control for" factors often disregarded in common study designs. These criteria, as formulated by the International Collaboration for Participatory Health Research [24], are primarily concerned with ensuring equitable participation within the research process and describing the primary characteristics of such a process.

For example, the appraisal of evidence in epidemiology is generally determined by specific norms for sampling, data collection and analysis, and also by a relatively distant positioning of the researchers as related to the people they are studying [109]. In participatory approaches, the shared decision-making in the research process often means making changes to typical data collection routines, with the advantage of generating evidence that is meaningful for academic researchers, practitioners, and community members $[73,85,86]$.

\section{Limitations of the review}

There are some limitations to consider regarding the results and the methods of this study. The main limitation is the extent of theoretical and methodical variation in the included studies underpinning our framework. Since there is no consistent body of literature regarding participatory approaches in epidemiology, the provided framework cannot claim to be comprehensive, overlooking certain domains of the research process. We therefore can only provide preliminary definitions that need further clarification. The search process within the scoping review also had limitations: First, there was an imbalance between scientific publications and grey literature (e.g. reports). Since many epidemiologic investigations are conducted outside the scientific community, for example by local or regional public health agencies, more effort should be made to explore this field. The grey literature could only be included in a limited way in our study, due to access issues. Second, we only included publications 
in English and German and therefore systematically excluded publications in other relevant languages.

\section{Conclusion}

Since public health "is about disease prevention and health promotion, lifestyle practices, cultures, the environment, social forces, historical traditions, and science in all its theoretical, methodological, and technological splendor", epidemiologists can collaborate with many partners to "acquire scientific knowledge that matters to public health and to apply the knowledge gained in public health practice" [110, p. 1804]. As outlined in this paper, participatory epidemiology embraces this longstanding thread $[59,74,111]$ and places emphasis on the mutual benefits of participatory approaches for academic researchers, public health practitioners, and the co-researching representatives of the populations being studied.

We have reviewed a large range of literature regarding stakeholder participation and other recent developments in the field of epidemiology, seeking to answer to questions of how participatory approaches are applied in epidemiology and what distinguishes them from nonparticipatory research, with the purpose of describing the implications for epidemiologic research practice. We found that participatory research partnerships in epidemiology can generate new, more comprehensive and more widely meaningful knowledge which can be applied more easily to make positive changes in people's health. The framework developed in this paper is meant to encourage epidemiological researchers and their partners in applying participatory principles to their work as a way to bridge the gap between description and action.

Currently, we are applying some aspects of our framework in PartKommPlus-German Research Consortium for Healthy Communities [112]. In PartKommPlus, participatory research is being applied to study the factors influencing the implementation and maintenance of health promotion strategies in German municipalities. In this context, the Robert Koch Institute (RKI) has established collaborations in order to explore participatory approaches to health reporting and epidemiology at both the municipal and the national levels.

\section{Key messages}

- Participatory epidemiology is a conceptual framework to enrich methodology. It offers ways to better contextualize epidemiologic research and provides more detailed definitions of the population under study. It is useful for working with heterogeneous data. It facilitates collaborative practices and offers innovative ways to disseminate findings.
- Participatory epidemiology fosters dialogue and partnership in research by allowing various frames of reference. This results in evidence which is useful for both academic researchers and public health practitioners.

\section{Abbreviations}

HIV: human immunodeficiency virus; NIDDM: non-insulin-dependent diabetes mellitus; STI: sexual transmitted infections.

\section{Authors' contributions}

The conceptual framework of participatory epidemiology was originally developed by MB, SJ, SH, CSH, and MTW as a part of the research agenda of "PartKommPlus-German Research Consortium for Healthy Communities" (www.partkommplus.de). MB initially conducted several handsearches and conducted the database-searches to explore the literature. MB, SJ, SH, CSH, MTW participated in drafting the paper, and MB, MTW prepared the final manuscript. All authors read and approved the final manuscript.

\section{Author details}

${ }^{1}$ Robert Koch Institute, Berlin, Germany. ${ }^{2}$ Catholic University of Applied Sciences Berlin, Berlin, Germany.

\section{Acknowledgements}

We thank our colleagues Nina Buttmann-Schweiger, Viviane Bremer, and Clarissa Lage Barbosa from Robert Koch Institute, Oliver Razum from Bielefeld University, and Jane Springett from University of Alberta who provided critique, insights, and expertise that greatly supported our research.

\section{Competing interests}

The authors declare that they have no competing interests.

\section{Funding}

This work was supported by the German Federal Ministry of Education and Research (BMBF) (Grant No. BMBF 01EL1423F). The funding body was not involved in the conduct of the study.

Received: 17 October 2016 Accepted: 21 January 2017

Published online: 10 February 2017

\section{References}

1. Breslow L, Detels R. Public health and epidemiology. In: Holland WW, Olsen J, duFlorey CV, editors. The development of modern epidemiology: personal reports from those who were there. Oxford: Oxford University Press; 2007.

2. Trinidad SB, Ludman EJ, Hopkins S, James RD, Hoeft TJ, Kinegak A, Lupie $H$, Kinegak R, Boyer BB, Burke W. Community dissemination and genetic research: moving beyond results reporting. Am J Med Genet Part A. 2015; 167:1542-50.

3. Gerhardus A, Breckenkamp J, Razum O. Evidence-based Public Health Prävention und Gesundheitsförderung im Kontext von Wissenschaft, Werten und Interessen. Med Klin. 2008;103:406-12.

4. Stallones RA. To advance epidemiology. Annu Rev Public Health. 1980;1:69-82.

5. Wing S. Limits of epidemiology. Med Glob Surviv. 1994;1:74-86.

6. Leung MW, Yen IH, Minkler M. Community based participatory research: a promising approach for increasing epidemiology's relevance in the 21st century. Int J Epidemiol. 2004;33:499-506.

7. Syme SL. The prevention of disease and promotion of health: the need for a new approach. Eur J Pub Health. 2007;17:329-30.

8. Krieger N. Epidemiology and the people's health. Theory and context. New York: Oxford University Press; 2011.

9. Galea S, Link BG. Six paths for the future of social epidemiology. Am J Epidemiol. 2013;178:843-9.

10. Krieger N. Epidemiology and the web of causation: has anyone seen the spider? Soc Sci Med. 1994;39:887-903. 
11. Shy CM, Walker AM. The failure of academic epidemiology: witness for the prosecution. Am J Epidemiol. 1997;145:479-84.

12. Diez-Roux AV. Bringing context back into epidemiology: variables and fallacies in multilevel analysis. Am J Public Health. 1998;88:216-22.

13. Susser M, Susser E. Choosing a future for epidemiology: II. From black box to Chinese boxes and eco-epidemiology. Am J Public Health. 1996:86:674-7.

14. Ompad DC, Galea S, Vlahov D. Urbanicity, urbanization, and the urban environment. In: Galea S, editor. Macrosocial determinants of population health. New York: Springer; 2007. p. 53-69.

15. Loue S, Galea S. Migration. In: Galea S, editor. Macrosicial determinants of population health. New York: Springer; 2007. p. 247-73.

16. Freudenberg N, Galea S. Corporate Practices. In: Galea S, editor. Macrosocial determinants of population health. New York: Springer; 2007. p. 71-104.

17. Hoebel J, Starker A, Jordan S, Richter M, Lampert T. Determinants of health check attendance in adults: findings from the cross-sectional German Health Update (GEDA) study. BMC Public Health. 2014;14:913.

18. Chowdhury PD, Emdad Haque C. Why is an integrated social-ecological systems (ISES) lens needed to explain causes and determinants of disease? A case study of dengue in Dhaka, Bangladesh. Adv Med Sociol. 2013;15:217-39.

19. Burrage H. Epidemiology and community health: a strained connection? Soc Sci Med. 1987;25:895-903.

20. Susser M, Susser E. Choosing a future for epidemiology: I. Eras and paradigms. Am J Public Health. 1996;86:668-73.

21. Gouda HN, Powles JW. The science of epidemiology and the methods needed for public health assessments: a review of epidemiology textbooks. BMC Public Health. 2014;14:139.

22. International Epidemiological Association. Epidemiology: still a basic science in public health? http://ieaweb.org/ epidemiology-still-a-basic-science-in-public-health.

23. Neumeyer-Gromen A, Bräunlich A, Zeeb H, Razum O. Theorie und praxis der epidemiologie. Teil l: Systematik theoretischer grundlagen der epidemiologie als zentrale fachdisziplin von "public health". Pravent Gesundh. 2006;1:190-7.

24. ICPHR. Position paper 1: what is participatory health research? Version: Mai 2013. Berlin: International Collaboration for Participatory Health Research; 2013.

25. Schwab M, Syme SL. On paradigms, community participation, and the future of public health. Am J Public Health. 1997;87:2049-51.

26. Sapienza JN, Corbie-Smith G, Keim S, Fleischman AR. Community engagement in epidemiological research. Ambul Pediatr. 2007;7:247-52.

27. Brown P. When the public knows better: popular epidemiology challenges the system. Environment. 1993;35:16-41.

28. Olsen A, Banwell C. Context and environment: the value of considering lay epidemiology. In: Banwell C, Ulijaszek S, Dixon J, editors. When culture impacts health: global lessons for effective health research. London: Elsevier; 2013. p.85-93.

29. Wing S, Grant G, Green M, Stewart C. Community based collaboration for environmental justice: south-east Halifax environmental reawakening. Environ Urban. 1996;8:129-40.

30. Freifeld CC, Chunara R, Mekaru SR, Chan EH, Kass-Hout T, lacucci AA, Brownstein JS. Participatory epidemiology: use of mobile phones for community-based health reporting. PLoS Med. 2010. doi:10.1371/journal.pmed.1000376.

31. Arksey H, O'Malley L. Scoping studies: towards a methodological framework. Int J Soc Res Methodol Theory Pract. 2005;8:19-32.

32. Shankardass K, Solar O, Murphy K, Greaves L, O'Campo P. A scoping review of intersectoral action for health equity involving governments. Int J Public Health. 2012;57:25-33.

33. Snilstveit B, Oliver S, Vojtkova M. Narrative approaches to systematic review and synthesis of evidence for international development policy and practice. J Dev Eff. 2012;4:409-29.

34. Jagosh J, Pluye P, Wong G, Cargo M, Salsberg J, Bush PL, Herbert CP, Green LW, Greenhalgh T, Macaulay AC. Critical reflections on realist review: insights from customizing the methodology to the needs of participatory research assessment. Res Synth Methods. 2014;5:131-41.

35. Pawson R. Evidence-based policy: the promise of 'realist synthesis' Evaluation. 2002;8:340-58.
36. Hardy Al. Ärzte, Ingenieure und städtische Gesundheit. Medizinische Theorien in der Hygienebewegung des 19. Jahrhunderts. Frankfurt a.M.: Campus; 2005

37 Wilson N, Dasho S, Martin AC, Wallerstein N, Wang CC, Minkler M. Engaging young adolescents in social action through photovoice: the Youth Empowerment Strategies (YES!) Project. J Early Adolesc. 2007;27:241-61.

38. Wang C, Burris MA. Photovoice: concept, methodology, and use for participatory needs assessment. Health Educ Behav. 1997;24:369-87.

39. Claudio L, Stingone JA. Improving sampling and response rates in children's health research through participatory methods. J Sch Health. 2008;78:445-51.

40. Loh P, Sugerman-Brozan J, Wiggins S, Noiles D, Archibald C. From asthma to AirBeat: community-driven monitoring of fine particles and black carbon in Roxbury, Massachusetts. Environ Health Perspect. 2002;110:297-301.

41. Oades LG, Law J, Marshall SL. Development of a consumer constructed scale to evaluate mental health service provision. J Eval Clin Pract. 2011;17:1102-7.

42. Merten S, Schaetti C, Manianga C, Lapika B, Chaignat CL, Hutubessy R, Weiss MG. Local perceptions of cholera and anticipated vaccine acceptance in Katanga Province, Democratic Republic of Congo. BMC Public Health. 2013;13:60.

43. Maar MA, Lightfoot NE, Sutherland ME, Strasser RP, Wilson KJ, Lidstone-Jones CM, Graham DG, Beaudin R, Daybutch GA, Dokis BR, et al. Thinking outside the box: aboriginal people's suggestions for conducting health studies with aboriginal communities. Public Health. 2011;125:747-53.

44. Brown ER, Holtby S, Zahnd E, Abbott GB. Community-based participatory research in the California Health Interview Survey. Prev Chronic Dis. 2005;2:1-8.

45. Thompson SJ, Gifford SM, Thorpe L. The social and cultural context of risk and prevention: food and physical activity in an urban aboriginal community. Health Educ Behav. 2000;27:725-43.

46. Wallerstein N. A participatory evaluation model for healthier communities: developing indicators for New Mexico. Public Health Rep. 2000;115:199-204.

47. Cameron M, Andersson N, McDowell I, Ledogar RJ. Culturally Safe epidemiology: oxymoron or scientific imperative. Pimatisiwin. 2010:8:89-116.

48. Murphy NJ. Citizen deliberation in setting health-care priorities. Health Expect. 2005;8:172-81.

49. Santos-Hövener C, Marcus U, Koschollek C, Oudini H, Wiebe M, Ouedraogo Ol, Thorlie A, Bremer V, Hamouda O, Dierks ML, et al. Determinants of HIV, viral hepatitis and STI prevention needs among African migrants in Germany; a cross-sectional survey on knowledge, attitudes, behaviors and practices. BMC Public Health. 2015;15:735.

50. Forrest JI, Stevenson B, Rich A, Michelow W, Pai J, Jollimore J, Raymond HF, Moore D, Hogg RS, Roth EA. Community mapping and respondentdriven sampling of gay and bisexual men's communities in Vancouver, Canada. Cult Health Sex. 2014;16:288-301.

51. Aronson RE, Wallis AB, O'Campo PJ, Schafer P. Neighborhood mapping and evaluation: a methodology for participatory community health initiatives. Matern Child Health J. 2007;11:373-83.

52. Voigtländer S, Berger U, Razum O. The impact of regional and neighbourhood deprivation on physical health in Germany: a multilevel study. BMC Public Health. 2010;10:403.

53. Ansumana R, Malanoski AP, Bockarie AS, Sundufu AJ, Jimmy DH, Bangura U, Jacobsen KH, Lin B, Stenger DA. Enabling methods for community health mapping in developing countries. Int J Health Geogr. 2010;9:56.

54. Smith MH. Community-based epidemiology: community involvement in defining social risk. J Health Soc Policy. 1998;9:51-65.

55. Smith A, Christopher S, McCormick AKHG. Development and implementation of a culturally sensitive cervical health survey: a communitybased participatory approach. Women Health. 2004;40:67-86.

56. Goldsmith Cwikel J. After epidemiological research: what next? Community action for health promotion. Public Health Rev. 1994;22:375-94.

57. Sandman PM. Emerging communication responsibilities of epidemiologists. J Clin Epidemiol. 1991;44:41-50. 
58. McDavitt B, Bogart LM, Mutchler MG, Wagner GJ, Green HD Jr, Lawrence SJ, Mutepfa KD, Nogg KA. Dissemination as dialogue: building trust and sharing research findings through community engagement. Prev Chronic Dis. 2016;13:E38.

59. Lilienfeld DE. Definitions of epidemiology. Am J Epidemiol. 1978;107:87-90.

60. Paul JR. President's address: Clinical epidemiology. J Clin Investig. 1938;17:539-41.

61. Schwartz S, Susser E, Susser M. A Future for epidemiology? Annu Rev Public Health. 1999;20:15-33.

62. Gordon RR, Gellert GA. Population health looking upstream. Lancet. 1994;343:856-7.

63. Schulte PA, Rothman N, Hainaut P, Smith MT, Boffetta P, Perera FP. Molecular epidemiology: linking molecular scale insights to population impacts. IARC Sci Publ. 2011;163:1-7.

64. Cornwall A, Jewkes R. What is participatory research? Soc Sci Med. 1995;41:1667-76.

65. An interview with Leonard Syme and others about the project can be found on youtube. http://tinyurl.com/zm6353k.

66. Brice P, Zimmern R. The public health genomic enterprise. In: Khoury MJ, Bedrosian SR, Gwinn M, Higgins JT, loannidis JP, Little J, editors. Human genome epidemiology building the evidence for using genetic information to improve health and prevent disease. Oxford: Oxford University Press; 2010

67. Little M. Assignments of meaning in epidemiology. Soc Sci Med. 1998:47:1135-45.

68. Krieger N. Social inequalities in health. In: Olsen J, Saracci R, Trichopoulos D, editors. Teaching epidemiology. Oxford: Oxford University Press; 2010.

69. Fleischer NL, Weber AM, Gruber S, Arambula KZ, Mascarenhas M, Frasure JA, Wang C, Syme SL. Pathways to health: a framework for health-focused research and practice. Emerg Themes Epidemiol. 2006;3:18.

70. Wright MT, Block M, Unger H. Partizipative Qualitätsentwicklung. In: Kolip P, Müller VE, editors. Qualität von Gesundheitsförderung und Prävention. Bern: Hans Huber; 2009. p. 157-75.

71. Karmaus W. Of jugglers, mechanics, communities, and the thyroid gland: how do we achieve good quality data to improve public health? Environ Health Perspect. 2001;109:863-9.

72. ICPHR. Position paper 2: participatory health research: a guide to ethical principals and practice. Version: October 2013. Berlin: International Collaboration for Participatory Health Research; 2013.

73. Cacari-Stone L, Wallerstein N, Garcia AP, Minkler M. The promise of community-based participatory research for health equity: a conceptual model for bridging evidence with policy. Am J Public Health. 2014;104:1615-23.

74. Tuomilehto J, Puska P. The changing role and legitimate boundaries of epidemiology: community-based prevention programmes. Soc Sci Med. 1987;25:589-98.

75. Rose G. Sick individuals and sick populations. Int J Epidemiol. 2001;30:427-32.

76. Krieger N. Who and what is a "population"? Historical debates, current controversies, and implications for understanding "population health" and rectifying health inequities. Milbank Q. 2012;90:634-81.

77. Weiss MG. Cultural epidemiology: an introduction and overview. Anthropol Med. 2001;8:5-29.

78. Trostle JA. Epidemiology and culture. Cambridge: Cambridge University Press; 2005.

79. Wallerstein NB, Yen IH, Syme SL. Integration of social epidemiology and community-engaged interventions to improve health equity. Am J Public Health. 2011;101:822-30.

80. Yen $I H$, Syme SL. The social environment and health: a discussion of the epidemiologic literature. Annu Rev Public Health. 1999;20:287-308.

81. Khoury MJ, Coates RJ, Fennell ML, Glasgow RE, Scheuner MT, Schully SD, Williams MS, Clauser SB. Multilevel research and the challenges of implementing genomic medicine. J Natl Cancer Inst Monogr. 2012;2012:112-20.

82. Andrews ML, Sanchez V, Carrillo C, Allen-Ananins B, Cruz YB. Using a participatory evaluation design to create an online data collection and monitoring system for New Mexico's Community Health Councils. Eval Program Plan. 2014;42:32-42.
83. Bhopal R. Paradigms in epidemiology textbooks: in the footsteps on Thomas Kuhn. Am J Public Health. 1999:89:1162-5.

84. Susser M. What is a cause and how do we know one? A grammar for pragmatic epidemiology. Am J Epidemiol. 1991;133:635-48.

85. Murphy K, Fafard P. Knowledge translation and social epidemiology: taking power, politics and values seriously. In: O'Campo P, Dunn JR, editors. Rethinking social epidemiology: towards a science of change. New York: Springer; 2012. p. 267-283.

86. de Leeuw E, McNess A, Crisp B, Stagnitti K. Theoretical reflections on the nexus between research, policy and practice. Crit Public Health. 2008:18:5-20.

87. Jagosh J, MacAulay AC, Pluye P, Salsberg J, Bush PL, Henderson J, Sirett $E$, Wong $G$, Cargo $M$, Herbert $C P$, et al. Uncovering the benefits of participatory research: implications of a realist review for health research and practice. Milbank Q. 2012;90:311-46.

88. Gold M, Dodd AH, Neuman M. Availability of data to measure disparities in leading health indicators at the state and local levels. J Public Health Manag Pract (JPHMP). 2008:14:S36-44.

89. Kroll LE, Lampert T. Regionalisierung von Gesundheitsindikatoren: Ergebnisse aus der GEDA-Studie 2009. Bundesgesundheitsblatt Gesundheitsforschung Gesundheitsschutz. 2012;55:129-40.

90. Van Bon-Martens MJH, Achterberg PW, Van De Goor IAM, Van Oers HAM. Towards quality criteria for regional public health reporting: concept mapping with Dutch experts. Eur J Public Health. 2012;22:337-42.

91. Bachinger E, Gerlinde G. Capacity Building für Gesundheitsberichterstattung. In: Kuhn J, Böcken J, editors. Verwaltete Gesundheit Konzepte der Gesundheitsberichterstattung in der Diskussion. Frankfurt a.M.: Mabuse-Verlag; 2009.

92. Rütten A, Abu-Omar K, Levin L, Morgan A, Groce N, Stuart J. Research note: social catalysts in health promotion implementation. J Epidemiol Community Health. 2008;62:560-5.

93. Mitchell SM, Shortell SM. The governance and management of effective community health partnerships: a typology for research, policy, and practice. Milbank Q. 2000;78:241-89.

94. Kendall E, Muenchberger H, Sunderland N, Harris M, Cowan D. Collaborative capacity building in complex community-based health partnerships: a model for translating knowledge into action. J Public Health Manag Pract. 2012;18:E1-13.

95. Israel BA, Krieger J, Vlahov D, Ciske S, Foley M, Fortin P, Guzman JR, Lichtenstein R, McGranaghan R, Palermo AG, Tang G. Challenges and facilitating factors in sustaining community-based participatory research partnerships: lessons learned from the Detroit, New York City and Seattle urban research centers. J Urban Health Bull NY Acad Med. 2006:83:1022-40.

96. Taylor Bishop Scott J, Abraczinskas M, Johnson VA, Cook JR, Kilmer RP, Daniels EN. Building capacity in child welfare to screen for mental health challenges: lessons learned. Prog Community Health Partnersh Res Educ Action. 2014;8:187-95.

97. Diver SW, Higgins MN. Giving back through collaborative research: towards a practice of dynamic reciprocity. J Res Pract. 2014;10:M9.

98. Morse J. Mixed method design: principles and procedures. Walnut Creek: Left Coast Press; 2009.

99. Karbach U, Stamer M, Holmberg C, Güthlin C, Patzelt C, Meyer T. Qualitative research in health services research-discussion paper, part 2: qualitative research in health services research in Germany-an overview. Gesundheitswesen. 2012;74:516-25.

100. Ismail MM, Gerrish K, Naisby A, Salway S, Chowbey P. Engaging minorities in researching sensitive health topics by using a participatory approach. Nurse Res. 2014;22:44-8.

101. Draper AK, Hewitt G, Rifkin S. Chasing the dragon: developing indicators for the assessment of community participation in health programmes. Soc Sci Med. 2010;71:1102-9.

102. Razum O, Gerhardus A. Editorial: methodological triangulation in public health research —advancement or mirage? Trop Med Int Health. 1999;4:243-4

103. Rutherford GW, McFarland W, Spindler H, White K, Patel SV, AberleGrasse J, Sabin K, Smith N, Taché S, Calleja-Garcia JM, Stoneburner RL. Public health triangulation: approach and application to synthesizing data to understand national and local HIV epidemics. BMC Public Health. 2010;10:477. 
104. Pluye P, Hong QN. Combining the power of stories and the power of numbers: mixed methods research and mixed studies reviews. Annu Rev Public Health. 2014;35:29-45.

105. Pawson R, Greenhalgh T, Harvey G, Walshe K. Realist review-a new method of systematic review designed for complex policy interventions. J Health Serv Res Policy. 2005;10:21-34.

106. Denzin NK. Sociological methods: a sourcebook. Chicago: Aldine Transaction; 1970.

107. Stephens C. Participation in different fields of practice: using social theory to understand participation in community health promotion. J Health Psychol. 2007;12:949-60.
108. Porta M. A dictionary of epidemiology. Oxford: Oxford University Press; 2008.

109. Rychetnik L, Frommer M, Hawe P, Shiell A. Criteria for evaluating evidence on public health interventions. J Epidemiol Community Health. 2002:56:119-27.

110. Weed DL, McKeown RE. Science and social responsibility in public health. Environ Health Perspect. 2003;111:1804-8.

111. Higginson J, Chu F. Ethical considerations and responsibilities in communicating health risk information. J Clin Epidemiol. 1991;44:51-6.

112. PartKommPlus. www.partkommplus.de.

\section{Submit your next manuscript to BioMed Central and we will help you at every step:}

- We accept pre-submission inquiries

- Our selector tool helps you to find the most relevant journal

- We provide round the clock customer support

- Convenient online submission

- Thorough peer review

- Inclusion in PubMed and all major indexing services

- Maximum visibility for your research

Submit your manuscript at

www.biomedcentral.com/submit 